OPEN ACCESS

Edited by:

Joel Guiot,

Centre National de la Recherche

Scientifique (CNRS), France

Reviewed by:

Zhonghui Liu,

The University of Hong Kong,

Hong Kong

Haibin Wu,

Chinese Academy of Sciences, China

Xin Jia,

Nanjing Normal University, China

*Correspondence:

Minmin Ma

mamm@|zu.edu.cn

Specialty section:

This article was submitted to

Paleoecology,

a section of the journal

Frontiers in Ecology and Evolution

Received: 12 March 2020

Accepted: 08 May 2020

Published: 09 June 2020

Citation:

Du L, Ma M, Lu Y, Dong J and

Dong $G$ (2020) How Did Human Activity and Climate Change Influence Animal Exploitation During 7500-2000

$B P$ in the Yellow River Valley, China?

Front. Ecol. Evol. 8:161.

doi: 10.3389/fevo.2020.00161

\section{How Did Human Activity and Climate Change Influence Animal Exploitation During 7500-2000 BP in the Yellow River Valley, China?}

\author{
Linyao Du ${ }^{1}$, Minmin $\mathrm{Ma}^{1 *}$, Yiwen $\mathrm{Lu}^{1}$, Jiajia Dong ${ }^{1}$ and Guanghui Dong ${ }^{1,2}$ \\ ${ }^{1}$ MOE Key Laboratory of Western China's Environmental Systems, College of Earth and Environmental Sciences, Lanzhou \\ University, Lanzhou, China, ${ }^{2}$ CAS Center for Excellence in Tibetan Plateau Earth Sciences, Chinese Academy of Sciences \\ (CAS), Beijing, China
}

The mid-late Holocene witnessed the rapid development of Neolithic and Bronze cultures in the Yellow River Valley (YRV) of northern China. Spatio-temporal patterns of plant utilization during this period and its influencing factors have been intensively discussed, whereas the variation in animal exploitation in relation to climate change and human activities has not been adequately studied. In this paper, we reviewed zooarchaeological data obtained from 38 Neolithic and Bronze sites in YRV, and compared them with paleoclimate and archaeological records, to reconstruct the trajectory of animal utilization in this area between 7500 and $2000 \mathrm{BP}$ and discern the influencing factors driving it. The results revealed that animal exploitation was mainly sourced from wildlife between 7500 and $6000 \mathrm{BP}$, shifting to omnivorous livestock sources in the period of 6000-4000 BP except in the northeast Tibetan Plateau. During 4000-2000 BP, however, omnivorous and herbivorous livestock had come to dominate humans' subsistence on animals, which nonetheless showed substantial spatio-temporal variation in the YRV. Further analysis suggests that animal exploitation in the Neolithic and Bronze YRV were both directly affected by human activities, while climate change might have influenced the environment surrounding human settlements and, indirectly, their choice of animals to exploit. This work provides new perspectives for exploring the changing patterns of human-environment interactions in the YRV during the mid-late Holocene.

\footnotetext{
Keywords: zooarchaeological analysis, human adaptation, human-environment interaction, Yellow River Valley,
} Neolithic and Bronze periods

\section{INTRODUCTION}

Interactions between human activity and environmental change in prehistoric and historical periods are topics of increasing concern over the last two decades (Dearing et al., 2006; Walsh, 2013; Dong, 2018; Feng et al., 2019), especially the influence of climate change on the evolution of civilizations and human behavior during the mid-late Holocene (Staubwasser et al., 2003; Kuper and Kröpelin, 2006; Bevan et al., 2017; Wu et al., 2018). During this pivotal period, when human populations grew and civilizations developed at an unprecedented speed, the climate also changed significantly (McEvedy and Jones, 1985; Mayewski et al., 2004; Fagan and Scarre, 2016). Human lifestyles in different areas of the Old World had evidently become transformed in the late Neolithic 
period (ca. 7000-5000 BP), largely due to the diffusion of new technologies (especially agricultural and livestock production) across Eurasia (Chen et al., 2015a; Pokharia et al., 2017; Liu et al., 2019), which significantly influenced human-environment interactions and the trajectory of social development (Primavera et al., 2017; Dong et al., 2019).

The Yellow River Valley (YRV) in northern China is one of the planet's earliest cradles for the origin and development of Neolithic cultures. Broomcorn and foxtail millet, and pig and dog, were all domesticated in the YRV and its surrounding areas during the early Holocene (Luo and Zhang, 2008; Li et al., 2010; Zhao, 2011), while intensive rain-fed agriculture based on milletcultivation had been established in the YRV's middle areas during 7000-6000 BP (Zhao, 2014; Dong et al., 2016b). Then Neolithic cultures expanded, synchronously and extensively, along the YRV with the diffusion of farming groups (Dong G. et al., 2017; Li et al., 2019); this could have been promoted by favorable climate during the middle Holocene (Jia et al., 2013; Chen et al., 2015b). Crops and livestock that were first domesticated in West Asia (wheat, barley, cattle, and sheep, to name a few) had been introduced into the YRV at ca. 4000 BP (Lee et al., 2007; Long et al., 2018), after which the human subsistence strategy differentiated in various regions of the YRV during the Bronze Age (Cheung et al., 2019; Li et al., 2020), when declines in both overall temperature and precipitation occurred (Marcott et al., 2013; Chen et al., 2015b).

Spatial-temporal variation in the subsistence on plants and human diets in northern China during Neolithic and Bronze periods, including the YRV, has been intensively discussed in recent years, leading to the view that it was apparently affected by both climate change and culture evolution during the mid-late Holocene (Ma et al., 2016; Dong Y. et al., 2017; An et al., 2019). However, the spatial-temporal pattern of animal exploitation in the YRV during that period and its relationship with climate variation and human activities remain understudied. Therefore, here we systematically reviewed the published zooarchaeological data from Neolithic and Bronze sites in the YRV, comparing them with high-quality paleoclimate records and archaeological evidence currently available, to investigate the history of changes to animal exploitation in the YRV, and how this may have been influenced by climate change and human activities during the period of ca. $7500-2000 \mathrm{BP}$.

\section{DATA SOURCES}

Complete zooarchaeological data from 38 excavated mid-late Neolithic and Bronze sites in YRV were amassed, which includes nine sites with animal remains that were unearthed from archaeological strata of different phases (Table 1). It is now a common practice to use NISP (i.e., Number of Identified Specimen) and MNI (Minimum Number of Individuals) to describe such faunal remains. However, the corresponding systematic MNI data can be hardly found in some earlypublished studies (e.g., Lu and Zhou, 1990; Zhou, 1994; Liu et al., 2001). According to existing reports that are complete, the trends reflected by either NISP or MNI are usually similar (e.g., Hu et al., 2011a; Yu, 2011; Wang H., 2019). Accordingly, here we used NISP to discuss patterns of animal exploitation on a larger spatial-temporal scale. To ensure the data collected in this work were valid for their statistical analysis, all 38 sites referred to in this study are settlement sites, from which at least 100 identified NISP of faunal remains are cataloged. The respective age of these sites is ca. $7500-2000 \mathrm{BP}$, determined primarily by published radiocarbon dates, and secondly by the attributes of their artifact assemblages. Geographical locations and detailed information of those 38 selected sites are shown in Figure $\mathbf{1}$ and Table $\mathbf{1}$.

To explore spatial patterns of animal exploitation in different phases of the YRV, we divided the study area into three major geographical zones: the upper YRV encompassing Qinghai, Gansu, and Ningxia Provinces; the middle YRV, encompassing mid-southern Inner Mongolia, Shaanxi, and Shanxi Provinces and most of Henan Province; and the lower YRV, consisting of Shandong Province and the eastern region of Henan Province (http://www.yrcc.gov.cn/hhyl/hhgk/hd/lyfw/ 201108/t20110814_103452.html). To facilitate assessment of the spatio-temporal distribution of animal exploitation in the YRV, we divided the zooarchaeological data into six stages, according to the limitation of temporal resolution of the current zooarchaeological and relative palaeo-vegetation data set.

Furthermore, we selected a North China temperature reconstruction profile (Hou and Fang, 2012), a precipitation record from Gonghai Lake (Chen et al., 2015b) and a proxy of vegetation condition (Zhao and $\mathrm{Yu}, 2012$ ) to construct the paleoclimate and paleoenvironment of YRV during 80002000 BP. Based on the summary of radiocarbon dates from archaeological sites of China (refer to Dong et al., 2019), radiocarbon dates from sites in the YRV were selected to build a summed probability distribution (SPD) for revealing the fluctuations and trends of people population in this area during 8000-2000 BP. For the analysis of the assemblage of wild mammals, they were classified as forest wildlife (e.g., spotted deer, wild boar, rhinoceros), grassland wildlife (e.g., hare, wild horse, marmot), wetland wildlife (e.g., elk, water buffalo, river deer) and other wildlife according to their living habits. In making these categorizations, we referred to the primary literature on taxonomic identification and also the Chinese Animal Atlas-Mammals (中国动物图谱兽类) (Xia and Gao, 1988). The detailed information can be found in the Supplementary Table S1.

\section{RESULTS AND DISCUSSION}

The variation in animal exploitation during the Neolithic and Bronze periods is closely related to the domestication and diffusion of livestock across the Old World. The domestication of dog can be traced back to ca. 33000 BP (Wang et al., 2016), while the earliest remains of domestic dog in northern China have been identified from the Nanzhuangtou site (ca. $10000 \mathrm{BP}$ ) (Yuan, 2010). Pig was also independently domesticated in China (Larson et al., 2005), as humans began to utilize the domestic pig at the Jiahu site, located in Henan Province, during 9000$8000 \mathrm{BP}$ (Luo and Zhang, 2008). Sheep/goat and cattle were firstly 
TABLE 1 | Names, NISP (Number of Identified Specimen), major periods, locations, cultural phases, and references of all sites included in this study.

\begin{tabular}{|c|c|c|c|c|c|c|}
\hline ID & Site & NISP & Major period (BP) & Location & Cultural phase & References \\
\hline 2 & Andaqiha & 1195 & $5400-4500$ & Qinghai, Hualong & Majiayao Culture & Ren, 2017 \\
\hline 4 & Maojiaping & 1016 & $3000-2700$ & Gansu, Tianshui & Western Zhou Dynasty & Liu, 2019 \\
\hline 4 & Maojiaping & 4208 & $2700-2400$ & Gansu, Tianshui & Chunqiu Period & Liu, 2019 \\
\hline 4 & Maojiaping & 2384 & 2400-2200 & Gansu, Tianshui & Warring States Period & Liu, 2019 \\
\hline 5 & Xishan & 1769 & 2700-2200 & Gansu, Li county & Eastern Zhou Dynasty & Yu, 2011 \\
\hline 6 & Dadiwan & 974 & $7800-7300$ & Gansu, Tianshui & Early Yangshao Culture & Qi et al., 2006 \\
\hline 6 & Dadiwan & 5116 & $6500-5900$ & Gansu, Tianshui & Yangshao Culture & Qi et al., 2006 \\
\hline 6 & Dadiwan & 3581 & $5500-4900$ & Gansu, Tianshui & Late Yangshao Culture & Qi et al., 2006 \\
\hline 6 & Dadiwan & 4566 & $4900-4800$ & Gansu, Tianshui & Yangshao Culture-Qijia Culture & Qi et al., 2006 \\
\hline 7 & Wayaogou & 6094 & $6500-6000$ & Shaanxi, Tongchuan & Yangshao Culture & Wang, 2011 \\
\hline 12 & Xicha & 5830 & $3600-2200$ & Inner Mongolia, Hohhot & Shang Dynasty-Zhou Dynasty & Yang C., 2006 \\
\hline 13 & Yangguanzhai & 385 & $5600-4900$ & Shaanxi, Gaoling & Miaodigou Culture & Hu et al., 2011b \\
\hline 14 & Kangjia & 445 & $4200-4100$ & Shaanxi, Lintong & Longshan Culture & Liu et al., 2001 \\
\hline 15 & Jiangzhai & 2278 & $6700-6300$ & Shaanxi, Lintong & Yangshao Culture Banpo Type & Qi, 1988 \\
\hline 15 & Jiangzhai & 342 & $6500-5900$ & Shaanxi, Lintong & Yangshao Culture Shijia Type & Qi, 1988 \\
\hline 15 & Jiangzhai & 588 & $5600-4900$ & Shaanxi, Lintong & Yangshao Culture Xiwangcun Type & Qi, 1988 \\
\hline 15 & Jiangzhai & 334 & $4300-4000$ & Shaanxi, Lintong & Keshengzhuang Culture Phase II & Qi, 1988 \\
\hline 16 & Lingkoucun & 331 & $7300-6600$ & Shaanxi, Lintong & Lingkoucun Culture & Zhao, 2009 \\
\hline 16 & Lingkoucun & 119 & $6600-6200$ & Shaanxi, Lintong & Yangshao Culture & Zhao, 2009 \\
\hline 17 & Baijiacun & 747 & 7300-7000 & Shaanxi, Lintong & Baijiacun Culture & Zhou, 1994 \\
\hline 18 & Quanhucun & 4245 & $5600-5100$ & Shaanxi, Hua county & Miaodigou Culture & $\mathrm{Hu}, 2014$ \\
\hline 19 & Xinglefang & 318 & $5900-5600$ & Shaanxi, Huayin & Miaodigou Culture & Hu et al., 2011a \\
\hline 24 & Erlitou & 15344 & $3600-3500$ & Henan, Yanshi & Erlitou Culture Phase IV & Yang J., 2006 \\
\hline 24 & Erlitou & 951 & 3600-3300 & Henan, Yanshi & Lower Erligang Culture & Yang J., 2006 \\
\hline 24 & Erlitou & 4569 & $3600-3300$ & Henan, Yanshi & Upper Erligang Culture & Yang J., 2006 \\
\hline 25 & Meishan & 299 & 3900-3600 & Henan, Pingdingshan & Longshan Culture & You et al., 2017 \\
\hline 26 & Huadizui & 4373 & $3800-3700$ & Henan, Gongyi & Xinzhai Culture & Liu, 2014 \\
\hline 27 & Xinzhai & 494 & 4000-3900 & Henan, Xinmi & Xinzhai Culture Phase I & $\begin{array}{l}\text { Aurora Center for the study of } \\
\text { Ancient Civilizations, Peking } \\
\text { University and Zhengzhou } \\
\text { Municipal Institute of Archaeology } \\
\text { and Cultural Relics, } 2008\end{array}$ \\
\hline 27 & Xinzhai & 3510 & 3800-3700 & Henan, Xinmi & Xinzhai Culture Phase II & $\begin{array}{l}\text { Aurora Center for the study of } \\
\text { Ancient Civilizations, Peking } \\
\text { University and Zhengzhou } \\
\text { Municipal Institute of Archaeology } \\
\text { and Cultural Relics, } 2008\end{array}$ \\
\hline 27 & Xinzhai & 600 & 3750 & Henan, Xinmi & Xinzhai Culture Phase III & $\begin{array}{l}\text { Aurora Center for the study of } \\
\text { Ancient Civilizations, Peking } \\
\text { University and Zhengzhou } \\
\text { Municipal Institute of Archaeology } \\
\text { and Cultural Relics, } 2008\end{array}$ \\
\hline 28 & Xishan & 5720 & 5500-4700 & Henan, Zhengzhou & Yangshao Culture & Chen, 2006 \\
\hline 29 & Shangpo & 1013 & 3800-3500 & Henan, Zhumadian & Erlitou Culture & Yang, 2018 \\
\hline
\end{tabular}


TABLE 1 | Continued

\begin{tabular}{|c|c|c|c|c|c|c|}
\hline ID & Site & NISP & Major period (BP) & Location & Cultural phase & References \\
\hline 30 & $\begin{array}{l}\text { Yinxu } \\
\text { Xiaomintun }\end{array}$ & 41720 & $3300-3000$ & Henan, Anyang & Late Shang Dynasty & Li, 2009 \\
\hline 30 & Yinxu Baijiafen & 9451 & $3300-3000$ & Henan, Anyang & Late Shang Dynasty & Li, 2009 \\
\hline 30 & Yinxu Dasikong & 13360 & 3300-3000 & Henan, Anyang & Late Shang Dynasty & Wang H., 2019 \\
\hline 31 & Yuezhuang & 823 & $7800-7000$ & Shandong, Jinan & Houli Culture & Song, 2016 \\
\hline 32 & Zhuanglixi & 7594 & $4600-4000$ & Shandong, Zaozhuang & Longshan Culture & Song et al., 2012 \\
\hline 33 & Daxinzhuang & 458 & $3600-3000$ & Shandong, Jinan & Shang Dynasty & Song, 2010 \\
\hline 34 & Yinjiacheng & 193 & $4600-4000$ & Shandong, Jining & Longshan Culture & Lu and Zhou, 1990 \\
\hline 34 & Yinjiacheng & 171 & $3800-3500$ & Shandong, Jining & Yueshi Culture & Lu and Zhou, 1990 \\
\hline 34 & Yinjiacheng & 133 & $3600-2200$ & Shandong, Jining & Shang Dynasty-Zhou Dynasty & Lu and Zhou, 1990 \\
\hline 35 & Jiaojia & 7382 & $5000-4500$ & Shandong, Jinan & Middle-late Dawenkou Culture & Wang J., 2019 \\
\hline 36 & Dinggong & 8059 & $4600-4000$ & Shandong, Binzhou & Longshan Culture & Rao, 2014 \\
\hline 37 & Tangshan & 606 & $3600-3000$ & Shandong, Huantai & Yinshang Phase I & Song et al., 2010 \\
\hline 38 & Qianbu & 664 & 3600-3000 & Shandong, Huantai & Late Yinshang & Song et al., 2010 \\
\hline
\end{tabular}

ID corresponds to the number shown in Figure 1.

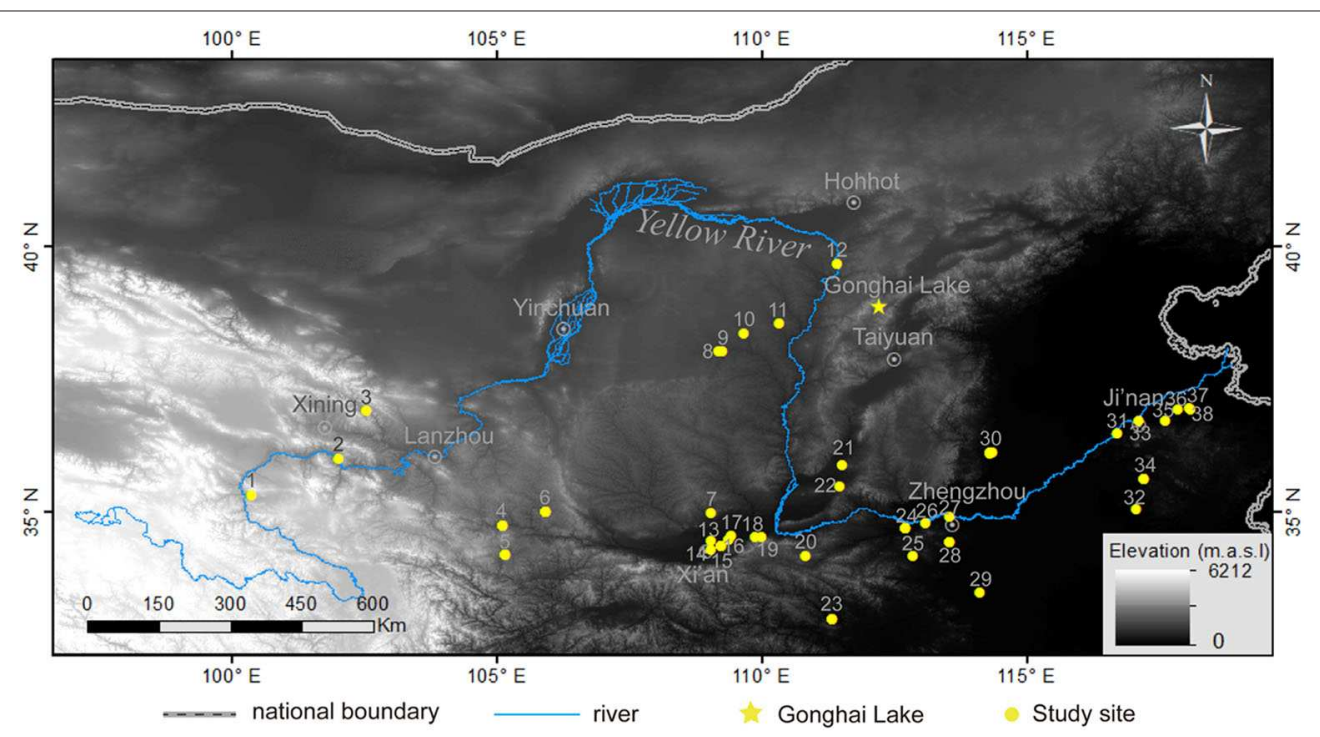

FIGURE 1 | Settlement site locations in China's Yellow River Valley referred to in this study. 1. Zongri; 2. Andaqiha; 3. Jinchankou; 4. Maojiaping; 5. Xishan; 6. Dadiwan; 7. Wayaogou; 8. Yangjiesha; 9. Dagujie; 10. Huoshiliang; 11. Shimao; 12. Xicha; 13. Yangguanzhai; 14. Kangjia; 15. Jiangzhai; 16 . Lingkoucun; 17. Baijiacun; 18. Quanhucun; 19. Xinglefang; 20. Xipo; 21. Taosi; 22. Zhoujiazhuang; 23. Longshangang; 24. Erlitou; 25. Meishan; 26. Huadizui; 27. Xishan; 28. Xinzhai; 29. Shangpo; 30. Yinxu Xiaomintun, Yinxu Baijiafen and Yinxu Dasikong; 31. Yuezhuang; 32. Zhuanglixi; 33. Daxinzhuang; 34. Yinjiacheng; 35. Jiaojia; 36. Dinggong; 37. Tangshan, and; 38. Qianbu.

domesticated in West Asia ca. $10000 \mathrm{BP}$, and introduced between 5600 and 4000 BP into northern China (Flad et al., 2007); but there, the remains of these herbivorous livestock were frequently identified only from sites younger than 4300 BP (Brunson et al., 2016; Hu et al., 2016). The horse could have been domesticated in Kazakhstan ca. 5500 BP (Outram et al., 2009), after which it was imported into northern China during 4000-3000 BP (Yuan, 2010). Although other livestock including chicken and camel were also brought into northern China before 2000 BP (Deng et al., 2013; You et al., 2014), their remains have been sporadically identified from Bronze sites in the YRV, and the NISP totals of those livestock at the 38 sites examined in this paper are negligible when compare to those of pig, dog, sheep, cattle and horse, thus we excluded them from this present work's discussion.

\section{Spatial-Temporal Changes in Animal Exploitation in the YRV During 7500-2000 BP}

Based on the NISP assemblages of animal remains identified from 38 Neolithic and Bronze sites in the YRV (Table 1), the spatial patterns of animal exploitation in the study area were 


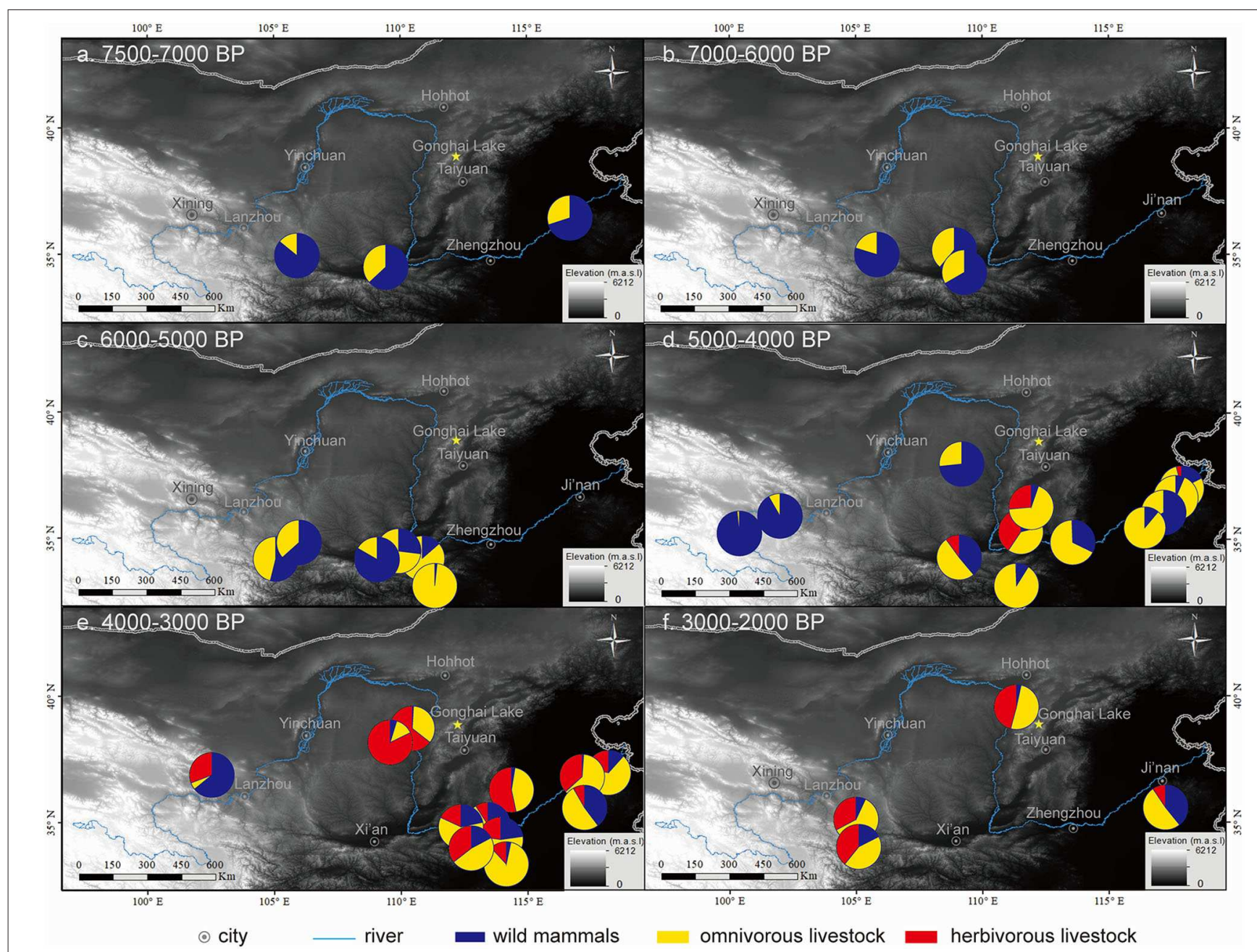

FIGURE 2 | Spatial-temporal patterns of animal assemblages (Number of Identified Specimen) from sites dating to $7500-2000$ BP in Yellow River Valley. (a) Animal assemblages from sites dating to 7500-7000 BP. (b) Animal assemblages from sites dating to 7000-6000 BP. (c) Animal assemblages from sites dating to 6000-5000 BP. (d) Animal assemblages from sites dating to 5000-4000 BP. (e) Animal assemblages from sites dating to 4000-3000 BP. (f) Animal assemblages from sites dating to 3000-2000 BP.

obviously different among 7500-6000, 6000-4000 and 40002000 BP (Figure 2).

The NISP percentage of wildlife remains in all but one (6/7) site dated to 7500-6000 BP exceeded those of livestock remains (Figures 2a,b), which suggested that hunting was the most important strategy of animal exploitation in the YRV during this period. Yet, at this time, the human subsistence strategy also differentiated markedly across areas of the YRV, in that humans mainly engaged in hunting-gathering activity in the upper YRV before 6000 BP (Rhode et al., 2007), while foxtail and broomcorn millet were cultivated in the middle and lower reaches of the Yellow River (Crawford et al., 2013; Zhao, 2017), even though intensive rain-fed agriculture had not been well-established in northern China (Dong et al., 2016b; Zhao, 2019). Thus, hunting game was an essential livelihood even for Neolithic groups during the 7500-6000 BP period in the YRV.

Millet cultivation became the primary subsistence strategy of humans in the middle YRV at ca. 6000 BP (Barton et al., 2009), followed by rain-fed agriculture that widely expanded with the diffusion of farming groups in the YRV (Dong G. et al., 2017; Zhao, 2019). Millet farmers had settled in the area below $2,500 \mathrm{~m}$ a.s.l. (above sea level) of the upper YRV, where they raised pig and dog between ca. 5200 and 4000 BP (Qi et al., 2006; An et al., 2010). The NISP percentages for remains of wild mammals and omnivorous livestock (pig and dog) from 4 sites dated to 6000-4000 BP in the upper YRV were $74.81 \%$ and $25.19 \%$, respectively, suggesting hunting remained the primary strategy of animal exploitation, especially in areas lying above 2,500 $\mathrm{m}$ a.s.l. which were unsuitable for cultivating cold-sensitive millets (An and Chen, 2007; Ren et al., 2020). However, the NISP percentage of omnivorous livestock exceeded wild mammals in most contemporaneous sites (14/19) in the middle and lower parts of the YRV, indicating animal husbandry had replaced hunting as the primary animal exploitation strategy in these areas during late Neolithic period. Sheep/goat and cattle were adopted as important animals for subsistence at several Longshan period (4600-4000 BP) sites, namely Taosi, Zhoujiazhuang, Kangjia and Dinggong; however, these imported herbivorous 
livestock were not yet widely utilized in the YRV before 4000 BP (Figure 2).

The NISP percentage for herbivorous livestock remains from sites dating to 4000-2000 BP underwent a remarkable increase, while that of wild mammals conspicuously declined, in comparison with the Neolithic periods (Figure 2). In the upper YRV, the NISP percentage for herbivorous livestock, omnivorous livestock, and wild mammal remains were, respectively, 30.65\%, $4.97 \%$, and $64.38 \%$ from sites dated to $4000-3000$ BP, changing correspondingly to $36.34 \%, 52.13 \%$, and $11.53 \%$ from sites of 3000-2000 BP. This result suggests animal husbandry gradually became the major subsistence strategy, as the proportions of herbivorous livestock - sheep/goat, cattle, horse and yak-in the remains were evidently enhanced in the study area during the Bronze Age. Yet domestic pig and dog were continually utilized as the major subsistence animals in the middle and lower YRV during 4000-2000 BP, as inferred from the NISP percentage of those omnivorous remains reaching $51.95 \%$ from 22 Bronze sites. Remains of herbivorous livestock could also be identified from all 22 Bronze sites, for which their NISP percentage was $32.83 \%$, indicating those imported animals were thoroughly integrated into human livelihoods in the YRV since 4000-2000 BP.

\section{Impact of Human Activity on Animal Exploitation in the YRV During 7500-2000 BP}

Human activity significantly influenced natural fauna on a regional scale since the late Pleistocene (Pushkina and Raia, 2008), and humans might have altered the species composition and geographical distribution of animals on continental-global scales during the Neolithic and Bronze periods (Tabata et al., 2018). Domesticated animals were spread widely into different areas of Afro-Eurasia by the diffusion of populations since the middle Holocene (Boivin et al., 2016), and this expansion of human settlements also destroyed natural habitats of various wild animals in late prehistoric periods (Ruddiman and Ellis, 2009; Lyons et al., 2015).

Human settlement intensity in the YRV was evidently low during 8000-6000 BP, as indicated by the SPD of radiocarbon dates (Figure 3D)-widely used as the index to reconstruct the intensity of human settlement during prehistoric periods (Rick, 1987; Wang et al., 2014; Yang et al., 2019)—which could have been sustained by hunting game, low-intensity crop cultivation, and breeding of omnivorous livestock. The impact of human activity on the natural environment in northern China during 8000-6000 BP was also limited (Dong et al., 2016b), further facilitating the maintenance of wildlife habitats on the landscape and presumably the prevalence of hunting activities in the YRV during that period.

On the one hand, intensive rain-fed agriculture emerged in the middle YRV ca. 6000 BP (Pechenkina et al., 2005; Barton et al., 2009), which triggered a rapid rise in the human settlement intensity (Figure 3D) and increased expansion of farming groups in the YRV during 6000-4000 BP (Dong et al., 2016b; Li et al., 2019). Together, this led to a greater dependence on animal husbandry that can provide a more steady meat resource than hunting game, especially on the northern China plain where conditions for the development of rain-fed agriculture are favorable. On the other hand, progress in livestock breeding technology could also have contributed to farming groups developing a reliance on more livestock resources. In northern China, farming groups expanded significantly in this period. The northernmost latitude of agricultural production reached southern West Liao River Basin, about $43.5^{\circ} \mathrm{N}$ (Jia et al., 2016a). And in the YRV, farming groups expanded to the marginal areas of the northeast Tibetan Plateau at ca. 5200 BP, but they mainly settled below 2,500 $\mathrm{m}$ a.s.l. during the late Neolithic period (Chen et al., 2015a). Since the mountainous and high-cold environment of the Tibetan Plateau is unsuitable for the production of millet crops, hunting game was the major recourse before the introduction of cold-tolerant barley and sheep varieties, accordingly then, wildlife continued to be the dominant animal for subsistence in the area during 6000-4000 BP.

Human settlement expanded toward higher elevation and latitude in China during the period of 4000-2000 BP (Dong et al., 2019), a shift promoted by the emergence of agropastoral activities between 4000 and 3000 BP (Chen et al., 2015a). While imported barley and wheat were adopted in the upper YRV as major staple much faster than in the middle and lower YRV, the flourishing of imported herbivorous livestock across the entire YRV can also be detected from its compiled zooarchaeological evidence (Figures 2e,f). Agriculture innovation promoted clear increase in the human settlement intensity of the upper YRV during 4000-3000 BP (Chen et al., 2015a), followed by evermore dependence on domestic animals, and the herding of herbivorous livestock in high elevation areas (Dong et al., 2016a). According to existing archaeological evidence (Li et al., 2009), the human settlement intensity in the middle and lower YRV increased continuously during the Bronze Age, which probably strengthened the significance of animal husbandry while diminishing the relevance of hunting activities in animal exploitation in that area during 4000-2000 BP.

\section{Impact of Climate Change on Animal Exploitation in the YRV Between 7500 and 2000 BP}

Climate fluctuations during the mid-late Holocene are considered an important influencing factor for the evolution of Neolithic and Bronze cultures, as well as vegetation change in the YRV (An et al., 2003; Tang et al., 2007; Hou et al., 2009), which further affected human activities and wildlife habitats. Here we summarized the NISP percentages for different animal assemblages in the YRV during 7500-2000 BP, and compared it with paleoclimate records and SPD of radiocarbon dates in the study area (Figure 3), to explore the impact of climate change on animal exploitation in YRV during 7500-2000 BP.

According to the temperature and precipitation reconstructions by Hou and Fang (2012) and Chen et al. (2015b), despite temperature fluctuations, the climate was warm and humid during 7500-6000 BP (Figures 3A,B), a period when forest cover in the East Asian monsoon margin region was relatively high while human settlement intensity in the YRV was low (Figures 3C,D). Similar climate patterns for the same period were reported by Xu et al. (2010) and Pei et al. (2019). The NISP 

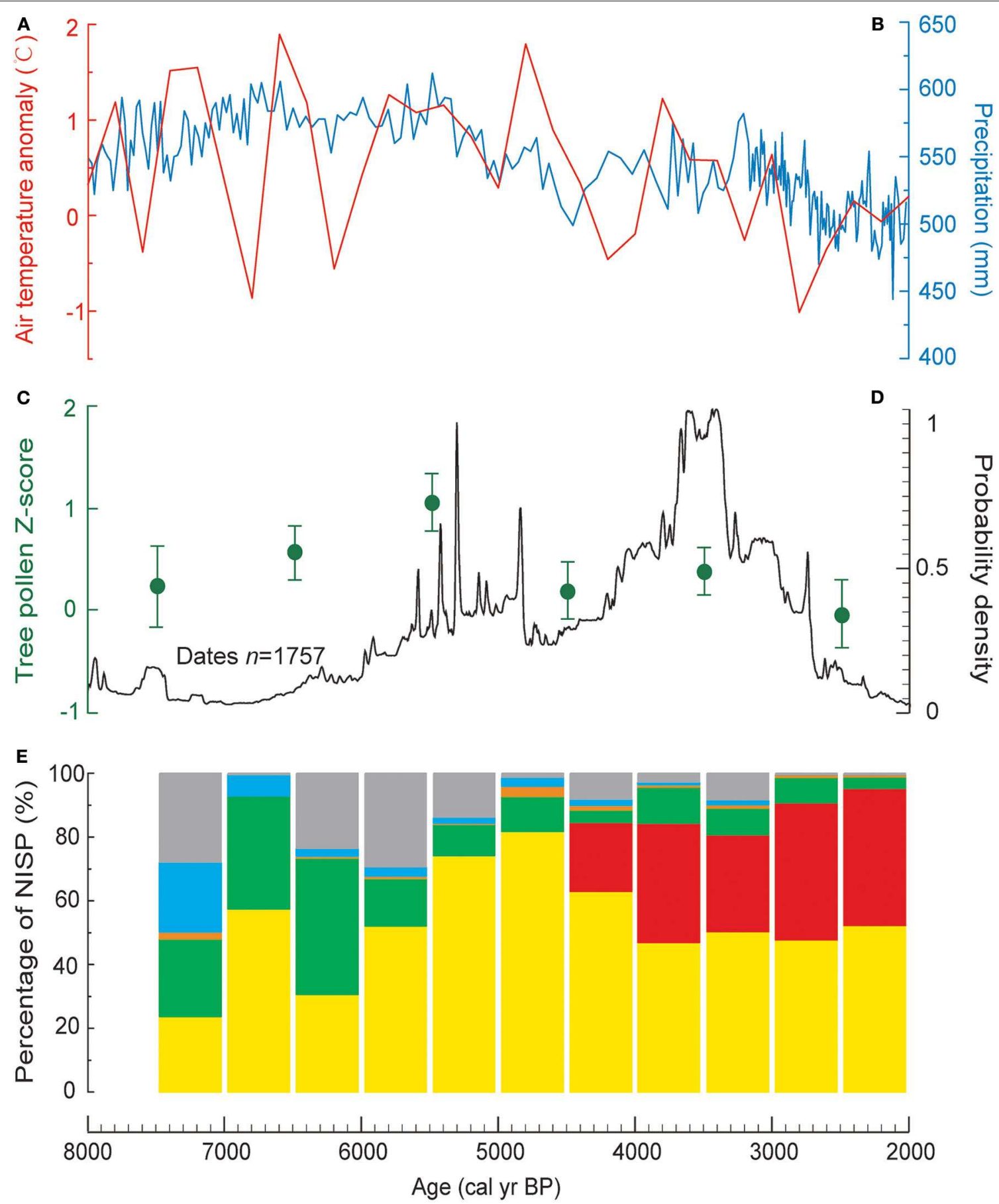

omnivorous livestock

grassland wildlife herbivorous livestock

wetland wildlife forest wildlife

unclassifiable wildlife

FIGURE 3 | Variation in the NISP (Number of Identified Specimen) percentages of faunal remains representing different habitats, compared with climate and vegetation changes, and the summed probability distribution of original radiocarbon dates from 8000 to 2000 BP. (A) North China temperature record (Hou and Fang, 2012). (B) Pollen-based annual precipitation regime, reconstructed from Gonghai Lake (Chen et al., 2015b). (C) Synthesized standard curve of tree pollen percentages in the monsoon margin region (lying between forest and steppe) (Zhao and Yu, 2012). (D) Summed probability distribution of original radiocarbon dates from 8000 to 2000 BP, revealing the trends and fluctuations in human population (Dong et al., 2019). (E) NISP percentage of livestock remains and wild mammal remains representing different habitats. 
percentage was obviously higher for remains of wild mammals than livestock during 7500-6000 BP, when the prevalence of forest and wetland wildlife was also much higher than found in the 6000-2000 BP period (Figure 3E) (detailed information can be found in the Supplementary Table S1). This result suggests the warm and wet climate during 7500-6000 BP provided habitats for wild animals before the intensification of rain-fed agriculture in the YRV, thereby facilitating hunting activities in this area.

In 6000-5000 BP, the climate was still relatively warm and wet, and forest cover in the East Asian monsoon margin region reached its maximum (Figures $3 \mathbf{A}-\mathbf{C}$ ), results consistent with other climate records (Yi et al., 2003; Xu et al., 2010; Pei et al., 2019). In the context of stable and suitable environmental conditions, human settlement intensity in the YRV evidently increased during that period (Figure 3D). As a result, the NISP percentage for omnivorous livestock increased remarkably (Figure 3E), especially in the middle and lower YRV (Figure 2c) which had been extensively settled by farming groups during 6000-5000 BP (Zhao, 2019). Temperature and precipitation clearly declined during the 5000-4000 BP period (Figures 3A,B), corresponding to the substantial reduction of forest in eastern monsoon China (Tarasov et al., 2006) and the East Asian monsoon margin (Figure 3C), and human settlement intensity in the YRV (Figure 3D). The NISP percentages for grassland wildlife and herbivorous livestock in the YRV significantly increased during 5000-4000 BP, probably due to the transformed natural environment in that period. Moreover, climate deterioration during 5000-4000 BP might have induced the shrinkage of habitats for wildlife, and consequently enhanced of significance of animal husbandry in the YRV, expect in its high elevation areas in northeast Tibetan Plateau (Figure 2d).

The climate has changed significantly during 4000-2000 BP. A dramatic climate deterioration occurred in North China around $3000 \mathrm{BP}$, with temperature and precipitation decline (Figures 3A,B). Meanwhile, forest cover in the East Asian monsoon margin region increased to some extent during 40003000 BP but then evidently dropped during 3000-2000 BP (Figure 3C). Regionally, the multi-proxy record for the upper YRV (Zhou et al., 2010), the loess-palaeosol sequence in the middle YRV (Zhao et al., 2007), and the pollen record from the lower YRV (Li et al., 2016) also suggest this dramatic climate change occurred. The NISP percentage for forest wildlife also rose during 4000-3000 BP and declined during 3000-2000 BP (Figure 3E), roughly tracking the variation in climate and forest cover. Both the living space and intensity of human settlement in northern China increased markedly during 40002000 BP (Dong et al., 2019), due to agriculture innovation brought via the trans-Eurasian exchange during the Bronze Age (Chen et al., 2015a), a period characterized by a relatively cold and dry climate (Figures 3A,B). For instance, the successful integration of imported crops (wheat and barley) and herding animals (sheep/goats, cattle, and horse, among others) in the indigenous subsistence system across the YRV (Zhou and GarvieLok, 2015) (Figures 2e,f) ensured the stability and prosperity of Bronze Age societies, by providing stable and sufficient crops and meat. Accordingly, the NISP percentage for herbivorous livestock underwent a notable increase between 4000 and 2000 BP. Though diversified agricultural production supported the human living, this climate deterioration event still influenced the human society in northern China, for example, the spatial distribution of human settlement (Jia et al., 2016b), which could result in the animal assemblage variation. Moreover, climate deterioration during the Bronze Age likely triggered an expansion of rangeland in the monsoon margin region, which is characterized by sensitivity to climate change (Xu et al., 2004; Feng et al., 2006), namely in the Hetao Region and western Loess Plateau, and this, too, probably promoted the flourishing of herbivorous livestock in both of those regions (Figures 2e,f).

\section{CONCLUSIONS}

Based on the analysis of zooarchaeological evidence from 38 Neolithic and Bronze sites in the YRV, we detected changing spatial patterns of animal exploitation during its different key phases. (1) Humans primarily relied on hunting game, accompanied by raising omnivorous livestock (pig and dog), to obtain meat in the YRV during 7500-6000 BP. Omnivorous livestock became the most important animal subsistence in the middle and lower YRV, whereas wildlife dominated in the upper YRV in 6000-4000 BP. However, during 4000-2000 BP, the significance of hunting game substantially declined, while that of imported herbivorous livestock (sheep/goat, cattle, and horse) evidently increased in the YRV, with omnivorous livestock still relied upon as the major source of meat during that period. (2) The occupied space and intensity of human settlement in the YRV rapidly increased since ca. $6000 \mathrm{BP}$, which triggered reductions in wildlife habitats and greater dependence on animal husbandry in the YRV during the late Neolithic and Bronze periods. Climate change could have influenced the evolution of vegetation and human societies in the YRV during the midlate Holocene, thereby influencing variation in the habitats available for wild animals, as well as promoting the adoption of imported livestock. The interaction between climate change and human activities eventually shaped the spatial-temporal patterns of animal exploitation in the YRV during 7500-2000 BP.

\section{DATA AVAILABILITY STATEMENT}

All datasets generated for this study are included in the article/Supplementary Material.

\section{AUTHOR CONTRIBUTIONS}

The study was designed by GD and MM. The data was collected by LD and analyzed by LD, YL, and JD. LD, MM, and GD wrote the manuscript.

\section{FUNDING}

This research was supported by the National Key Research \& Development Program of China (Grant No. 2018YFA0606402), Major Program of the National Natural Science Foundation of China (Grant No. 419912251), National Natural Science Foundation of China (Grant No. 41871076), Strategic 
Priority Research Program of the Chinese Academy of Sciences, Pan-Third Pole Environment Study for a Green Silk Road (Pan-TPE) (Grant No. XDA2004010101), and Fundamental Research Funds for the Central Universities (Grant No. lzujbky-2018-43).

\section{REFERENCES}

An, C., Feng, Z., Tang, L., and Chen, F. (2003). Environmental changes and cultural transition at 4 cal. ka BP in central Gansu (in Chinese). Acta Geogr. Sin. 58, 743-748. doi: 10.1007/s11442-010-0417-1

An, C., Ji, D., Chen, F., Dong, G., Wang, H., Dong, W., et al. (2010). Evolution of prehistoric agriculture in central Gansu Province, China: a case study in Qin'an and Li County (in Chinese). Chin. Sci. Bull. 55, 1925-1930. doi: $10.1007 /$ s11434-010-3208-2

An, J., and Chen, H. (2007). "The research of animal remains in Zongri culture site," in Zooarchaeology, ed Henan Institute of Cultural Relics and Archaeology (Beijing: Cultural Relics Press), 232-240 (in Chinese).

An, J., Kirleis, W., and Jin, G. (2019). Changing of crop species and agricultural practices from the Late Neolithic to the Bronze Age in the Zhengluo region, China. Archaeol. Anthropol. Sci. 11, 6273-6286. doi: 10.1007/s12520-019-00915-3

Aurora Center for the study of Ancient Civilizations, Peking University and Zhengzhou Municipal Institute of Archaeology and Cultural Relics (2008). Xinzhai Site in Xinmi-Report on Archaeological Excavations in 1999 and 2000 (in Chinese). Beijing: Cultural Relics Press.

Barton, L., Newsome, S. D., Chen, F., Wang, H., Guilderson, T. P., and Bettinger, R. L. (2009). Agricultural origins and the isotopic identity of domestication in northern China. Proc. Natl. Acad. Sci. U.S.A. 106, 5523-5528. doi: 10.1073/pnas.0809960106

Bevan, A., Colledge, S., Fuller, D., Fyfe, R., Shennan, S., and Stevens, C. (2017). Holocene fluctuations in human population demonstrate repeated links to food production and climate. Proc. Natl Acad. Sci. U.S.A. 114, E10524-E10531. doi: 10.1073/pnas.1709190114

Boivin, N. L., Zeder, M. A., Fuller, D. Q., Crowther, A., Larson, G., Erlandson, J. M., et al. (2016). Ecological consequences of human niche construction: examining long-term anthropogenic shaping of global species distributions. Proc. Natl. Acad. Sci. U.S.A. 113, 6388-6396. doi: 10.1073/pnas.1525200113

Brunson, K., He, N., and Dai, X. (2016). Sheep, cattle, and specialization: new zooarchaeological perspective on the Taosi Longshan. Int. J. Osteoarchaeol. 26, 460-475. doi: 10.1002/oa.2436

Chen, F., Dong, G., Zhang, D., Liu, X., Jia, X., An, C., et al. (2015a). Agriculture facilitated permanent human occupation of the Tibetan Plateau after 3600 BP. Science 347, 248-250. doi: 10.1126/science. 1259172

Chen, F., Xu, Q., Chen, J., Birks, H. J. B., Liu, J., Zhang, S., et al. (2015b). East Asian summer monsoon precipitation variability since the last deglaciation. Sci. Rep. 5:11186. doi: 10.1038/srep11186

Chen, Q. (2006). A study of the faunal remains from the Xishan site in Zhengzhou (in Chinese). Acta Archaeologica Sinica. 3, 385-418. doi: 10.1007/s11430-019-9389-9

Cheung, C., Zhang, H., Hepburn, J. C., Yang, D., and Richards, M. P. (2019). Stable isotope and dental caries data reveal abrupt changes in subsistence economy in ancient China in response to global climate change. PloS ONE 14:e0218943. doi: 10.1371/journal.pone. 0218943

Crawford, G. W., Chen, X., Luan, F., and Wang, J. (2013). A preliminary analysis on plant remains of the Yuezhuang site in Changqing District, Jinan, Shandong province (in Chinese). Jianghan Archaeol. 127, 107-116.

Dearing, J. A., Battarbee, R. W., Dikau, R., Larocque, I., and Oldfield, F. (2006). Human-environment interactions: learning from the past. Region. Environ. Change. 6, 1-16. doi: 10.1007/s10113-005-0011-8

Deng, H., Yuan, J., Song, G., Wang, C., and Masaki, E. (2013). Re-examination of the domestic chicken in ancient China (in Chinese). Kaogu 6, 83-96.

Dong, G. (2018). Understanding past human-environment interaction from an interdisciplinary perspective. Sci. Bull. 63, 1023-1024. doi: 10.1016/j.scib.2018.07.013

\section{SUPPLEMENTARY MATERIAL}

The Supplementary Material for this article can be found online at: https://www.frontiersin.org/articles/10.3389/fevo. 2020.00161/full\#supplementary-material

Dong, G., Li, R., Lu, M., Zhang, D., and James, N. (2019). Evolution of human-environmental interactions in China from the late Paleolithic to the Bronze Age. Progress Phys. Geogr. Earth Environ. 44, 233-250. doi: $10.1177 / 0309133319876802$

Dong, G., Ren, L., Jia, X., Liu, X., Dong, S., Li, H., et al. (2016a). Chronology and subsistence strategy of Nuomuhong culture in the Tibetan Plateau. Quat. Int. 426, 42-49. doi: 10.1016/j.quaint.2016.02.031

Dong, G., Yang, Y., Han, J., Wang, H., and Chen, F. (2017). Exploring the history of cultural exchange in prehistoric Eurasia from the perspectives of crop diffusion and consumption. Sci. China Earth Sci. 60, 1110-1123. doi: 10.1007/s11430-016-9037-x

Dong, G., Zhang, S., Yang, Y., Chen, J., and Chen, F. (2016b). Agriculture intensification and its impact on environment during Neolithic age in northern China (in Chinese). Chin. Sci. Bull. 61, 2913-2925. doi: 10.1360/N972016-00547

Dong, Y., Morgan, C., Chinenov, Y., Zhou, L., Fan, W., Ma, X., et al. (2017). Shifting diets and the rise of male-biased inequality on the central plains of China during eastern Zhou. Proc. Natl Acad. Sci. U.S.A. 114, 932-937. doi: $10.1073 /$ pnas. 1611742114

Fagan, B. M., and Scarre, C. (2016). Ancient Civilizations. London; New York, NY: Routledge.

Feng, Q., Yang, L., Deo, R. C., AghaKouchak, A., Adamowski, J. F., Stone, R., et al. (2019). Domino effect of climate change over two millennia in ancient China's Hexi Corridor. Nat. Sustain. 2, 957-961. doi: 10.1038/s41893-019-0397-9

Feng, Z., Tang, L., Wang, H., Ma, Y., and Liu, K. (2006). Holocene vegetation variations and the associated environmental changes in the western part of the Chinese Loess Plateau. Sci. Dir. 241, 440-456. doi: 10.1016/j.palaeo.2006.04.009

Flad, R., Yuan, J., and Li, S. (2007). "Zooarchaeological evidence for animal domestication in northwest China," in Late Quaternary Climate Change and Human Adaptation in Arid China, eds D. B. Madsen, F. Chen, and X. Gao (Amsterdam: Elsevier Press), 167-203.

Hou, G., and Fang, X. (2012). Characteristics analysis and synthetical reconstruction of regional temperature series of the Holocene in China (in Chinese). J. Palaeogeogr. 14, 243-252.

Hou, G., Liu, F., Liu, C., and Fang, X. (2009). Prehistorical cultural transition forced by environmental change in mid-Holocene in Gansu-Qinghai region. Acta Geogr. Sin. 64, 53-58.

$\mathrm{Hu}, \mathrm{S}$. (2014). "Analyses of faunal remains (in Chinese)," in The Quanhucun Site in Huaxian County-A Report of the 1997-Year Excavation, ed Shaanxi Provincial Institute of Archaeology, Weinan Municipal Administration of Cultural Relics and Tourism, and Huaxian County Administration of Cultural Relics and Tourism (Beijing: Cultural Relics Press), 595-661.

Hu, S., Sun, Z., Yang, L., Kang, N., Yang, M., and Li, X. (2013). Research on faunal remains from the Yangjiesha site in Hengshan County, Shaanxi Province (in Chinese). Acta Anthropol. Sinica. 32, 77-92. doi: 10.16359/j.cnki.cn11-1963/q.2013.01.008

Hu, S., Wang, W., Guo, X., Zhang, W., and Yang, M. (2011b). Faunal analysis of the animal remains found near the west gate of the settlement moat at Yangguanzhai site, Gaoling County, Shaanxi Province (in Chinese). Archaeol. Cult. Relics 6, 97-107. doi: 10.3969/j.issn.1000-7830.2011.06.012

Hu, S., Yang, L., Kang, N., Yang, M., and Li, X. (2012). An analysis of faunal remains from the Dagujie site in Hengshan, Shaanxi (in Chinese). Archaeol. Cult. Relics 4, 106-112. doi: 10.3969/j.issn.1000-7830.2012.04.014

Hu, S., Yang, M., Sun, Z., and Shao, J. (2016). Research on faunal remains from the 2012-2013 season excavation at the Shimao site in Shenmu, Shaanxi Procince (in Chinese). Archaeol. Cult. Relics 4, 109-121. doi: 10.3969/j.issn.1000-7830.2016.04.012

Hu, S., Yang, Q., and Yang, M. (2011a). Analysis on faunal remains from the Xinglefang site in Huayin, Shaanxi Province (in Chinese). Archaeol. Cult. Relics 6, 117-125. doi: 10.3969/j.issn.1000-7830.2011.06.014 
Hu, S., Zhang, P., and Yuan, M. (2008). A study on the faunal remains from the Huoshiliang site in Yulin, Shaanxi Province (in Chinese). Acta Anthropol. Sin. 27, 232-248. doi: 10.3969/j.issn.1000-3193.2008.03.005

Jia, X., Dong, G., Li, H., Brunson, K., Chen, F., Ma, M., et al. (2013). The development of Agriculture and its impact on cultural expansion during the late Neolithic in the western Loess Plateau, China. Holocene 23, 85-92. doi: $10.1177 / 0959683612450203$

Jia, X., Lee, H. F., Zhang, W., Wang, L., Sun, Y., Zhao, Z., et al. (2016a). Human-environment interactions West Liao River basin in northeastern China during the Holocene optimum. Quat. Int. 426, 10-17. doi: 10.1016/j.quaint.2016.01.011

Jia, X., Sun, Y., Wang, L., Sun, W., Zhao, Z., Lee, F. H., et al. (2016b). The transition of human subsistence strategies in relation to climate change during the Bronze Age in the West Liao River basin, Northeast China. Holocene 26, 781-789. doi: $10.1177 / 0959683615618262$

Kuper, R., and Kröpelin, S. (2006). Climate-controlled holocene occupation in the Sahara: motor of Africa's evolution. Science 313, 803-807. doi: 10.1126/science.1130989

Larson, G., Dobney, K., Albarella, U., Fang, M., Matisoo-Smith, E., Robins, J., et al. (2005). Worldwide phylogeography of wild boar reveals multiple centers of pig domestication. Science 307, 1618-1621. doi: 10.1126/science. 1106927

Lee, G. A., Crawford, G. W., Liu, L., and Chen, X. (2007). Plants and people from the early Neolithic to Shang periods in North China. Proc. Natl. Acad. Sci. U.S.A. 104, 1087-1092. doi: 10.1073/pnas.0609763104

Li, J., Qiao, Q., and Ren, X. (2010). Excavation to Nanzhuangtou site in Xushui County, Hebei in 1997 (in Chinese). Acta Archaeol. Sin. 3, 361-392.

Li, K., Gu, Y., and Liu, H. (2016). Holocene climate changes derived from sporepollen records and Neolithic culture succession in northern Henan plain (in Chinese). J. Jilin Univ. 46, 1449-1457. doi: 10.13278/j.cnki.jjuese.201605115

Li, X., Shang, X., Dodson, J., and Zhou, X. (2009). Holocene agriculture in the Guanzhong basin in NW China indicated by pollen and charcoal evidence. Holocene 19, 1213-1220. doi: 10.1177/0959683609345083

Li, X., Zhang, S., Lu, M., Qiu, M., Wen, S., and Ma, M. (2020). Dietary shift and social hierarchy from the Proto-Shang to Zhou Dynasty in the Central Plains of China. Environ. Res. Lett. 15:035002. doi: 10.1088/1748-9326/ab6783

Li, Y., Tian, J., Liu, F., Yang, B., Gu, K., Ranhman, Z. U., et al. (2019). Neolithic millet farmers contributed to the permanent settlement of the Tibetan Plateau by adopting barley agriculture. Natl. Sci. Rev. 6, 1005-1013. doi: $10.1093 / \mathrm{nsr} / \mathrm{nwz} 080$

Li, Z. (2009). The study on faunal remains from Anyang, the capital site of late Shang (in Chinese) (Dissertation). Graduate School of Chinese Academy of Social Sciences, Beijing, China.

Lin, M. (2011). Analyses on faunal remains from Longshangang site, in Xichuan County, Henan Province (in Chinese) (Dissertation). Shandong University, Ji'nan, China,

Liu, H. (2019). The research of animal remains of Maojiaping site in Tianshui, Gansu Province (in Chinese) (Dissertation). Northwest University, Xi'an, China.

Liu, L., Yan, Y., and Qin, X. (2001). The faunal remains unearthed at 1990 from Kangjia site in Lintong, Shaanxi (in Chinese). Huaxia Archaeol. 1, 3-24. doi: 10.3969/j.issn.1001-9928.2001.01.001

Liu, X., Jones, P. J., Matuzeviciute, G. M., Lister, D. L., An, T., Przelomska, N., et al. (2019). From ecological opportunism to multi-cropping: Mapping food globalisation in prehistory. Quat. Sci. Rev. 206, 21-28. doi: 10.1016/j.quascirev.2018.12.017

Liu, Y. (2014). Research of faunal remains from Huadizui site in Gongyi, Henan Province (in Chinese) (Dissertation). Graduate School of Chinese Academy of Social Sciences, Beijing, China.

Long, T., Leipe, C., Jin, G., Wagner, M., Guo, R., Schröder, O., et al. (2018). The early history of wheat in China from $14 \mathrm{C}$ dating and bayesian chronological modelling. Nat. Plants 4, 272-279. doi: 10.1038/s41477-0180141-x

Lu, H., and Zhou, C. (1990). "Identification report of animal and plant specimens unearthed at Yinjiacheng Site in Sichui County, Shandong Province (in Chinese)," in Sishui Yinjiacheng, ed Department of History, Shandong University (Beijing: Cultural Relics Press), 350-352.

Luo, Y., and Zhang, J. (2008). Re-study of pig bones unearthed from Jiahu site in Wuyang County, Henan (in Chinese). Kaogu 1, 90-96.
Lyons, S. K., Amatangelo, K. L., Behrensmeyer, A. K., Bercovici, A., Blois, J. L., Davis, M., et al. (2015). Holocene shifts in the assembly of plant and animal communities implicate human impacts. Nature 529, 80-83. doi: $10.1038 /$ nature 16447

Ma, M., Dong, G., Jia, X., Wang, H., Cui, Y., and Chen, F. (2016). Dietary shift after $3600 \mathrm{cal} \mathrm{yr} \mathrm{BP}$ and its influencing factors in northwestern China: evidence from stable isotopes. Quat. Sci. Rev. 145, 57-70. doi: 10.1016/j.quascirev.2016.05.041

$\mathrm{Ma}, \mathrm{X}$. (2007). The faunal remains from Xipo site in Lingbao, Henan Province and its related issues (in Chinese). Cult. Relics Central China 4, 48-61.

Marcott, S. A., Shakun, J. D., Clark, P. U., and Mix, A. C. (2013). A reconstruction of regional and global temperature for the past 11300 years. Science 339, 1198-1201. doi: 10.1126/science.1228026

Mayewski, P. A., Rohling, E. E., Stager, J. C., Karlén, W., Maasch, K. A., Meeker, L. D., et al. (2004). Holocene climate variability. Quat. Res. 62, 243-255. doi: 10.1016/j.yqres.2004.07.001

McEvedy, C., and Jones, R. (1985). Atlas of World Population History. England: Penguin Books Ltd.

Outram, A. K., Stear, N. A., Bendrey, R., Olsen, S., Kasparov, A., Zaibert, V., et al. (2009). The earliest horse harnessing and milking. Science 323, 1332-1335. doi: $10.1126 /$ science. 1168594

Pechenkina, E. A., Ambrose, S. H., Ma, X., and Benfer Jr, R. A. (2005). Reconstructing northern Chinese Neolithic subsistence practices by isotopic analysis. J. Archaeol. Sci. 32, 1176-1189. doi: 10.1016/j.jas.2005.02.015

Pei, Q., Zhang, D. D., Li, J., and Fei, J. (2019). Proxy-based temperature reconstruction in China for the Holocene. Quat. Int. 521, 168-174. doi: 10.1016/j.quaint.2019.06.032

Pokharia, A. K., Mani, B. R., Spate, M., Betts, A., and Srivastava, A. (2017). Early Neolithic agriculture (2700-2000 bc) and Kushan period developments (ad 100300): macrobotanical evidence from Kanispur in Kashmir, India. Veget. History Archaeobot. 27, 477-491. doi: 10.1007/s00334-017-0645-8

Primavera, M., D’Oronzo, C., Muntoni, I. M., Radina, F., and Fiorentino, G. (2017). Environment, crops and harvesting strategies during the II millennium BC: Resilience and adaptation in socio-economic systems of Bronze Age communities in Apulia (SE Italy). Quat. Int. 436, 83-95. doi: 10.1016/j.quaint.2015.05.070

Pushkina, D., and Raia, P. (2008). Human influence on distribution and extinctions of the late Pleistocene Eurasian megafauna. J. Hum. Evol. 54, 769-782. doi: 10.1016/j.jhevol.2007.09.024

Qi, G. (1988). “An analysis of the fauna of Neolithic sites in Jiangzhai (in Chinese)," in Jiangzhai-The Excavation Report of a Neolithic Site, ed Banpo Museum (Beijing: Cultural Relics Press), 504-538.

Qi, G., Lin, Z., and An, J. (2006). "Report of identification of faunal remains from the Dadiwan Site (in Chinese)," in Qin'an Dadiwan, ed Gansu Provincial Institute of Cultural Relics and Archaeology (Beijing: Cultural Relics Press), $861-910$.

Rao, X. (2014). Research on the faunal remains of Longshan culture in Dinggong site Zouping (in Chinese) (Dissertation). Shandong University, Ji'nan, China.

Ren, L. (2017). A study on animal exploitation strategies from the late Neolithic to Bronze Age in northeastern Tibetan Plateau and its surrounding areas, China (in Chinese) (Dissertation). Lanzhou University, Lanzhou, China.

Ren, L., Dong, G., Liu, F., d'Alpoim-Guedes, J., Flad, R. K., Ma, M., et al. (2020). Foraging and farming: archaeobotanical and zooarchaeological evidence for Neolithic exchange on the Tibetan Plateau. Antiquity. doi: 10.15184/aqy.2020.35. [Epub ahead of print].

Rhode, D., Zhang, H., Madsen, D. B., Gao, X., Brantingham, P. J., Ma, H., et al. (2007). Epipaleolithic/early Neolithic settlements at Qinghai Lake, western China. J. Archaeol. Sci. 3, 600-612. doi: 10.1016/j.jas.2006.06.016

Rick, J. W. (1987). Dates as data: an examination of the Peruvian preceramic radiocarbon record. Am. Antiquity 52, 55-73. doi: 10.2307/281060

Ruddiman, W. F., and Ellis, E. C. (2009). Effect of per-capita land use changes on Holocene forest clearance and CO2 emissions. Quat. Sci. Rev. 28, 3011-3015. doi: 10.1016/j.quascirev.2009.05.022

Song, Y. (2010). "Analysis of the faunal remains excavated in 1984 from Daxinzhuang site, Ji'nan City (in Chinese)," in East Asia Archaeology V, ed Institute of Cultural Heritage of Shandong University (Beijing: Science Press), 346-355.

Song, Y. (2016). Comprehensive analysis of animal remains in the Houli culture period in Ji'nan (in Chinese). Huaxia Agric. 3, 53-59. 
Song, Y., Song, J., and He, D. (2012). "The faunal remains analysis of Zhuanglixi Longshan culture site, Tengzhou, Shandong (in Chinese)," in East Asia Archaeology IX, ed Institute of Cultural Heritage of Shandong University (Beijing: Science Press), 609-626.

Song, Y., Yan, S., Tong, P., and Wei, C. (2010). "The study of faunal remains from Tangshan and Qianbu, Huantai County, Shandong Province (in Chinese)," in East Asia Archaeology V, ed Institute of Cultural Heritage of Shandong University (Beijing: Science Press), 315-345.

Staubwasser, M., Sirocko, F., Grootes, P. M., and Segl, M. (2003). Climate change at the $4.2 \mathrm{ka}$ BP termination of the Indus valley civilization and Holocene south Asian monsoon variability. Geophys. Res. Lett. 30:1425. doi: 10.1029/2002GL016822

Tabata, R., Kawaguchi, F., Sasazaki, S., Yamamoto, Y., Bakhtin, M., Kazymbet, P., et al. (2018). The Eurasian steppe is an important goat propagation route: a phylogeographic analysis using mitochondrial DNA and Ychromosome sequences of Kazakhstani goats. Anim. Sci. J. 90, 317-322. doi: $10.1111 /$ asj.13144

Tang, L., Li, C., An, C., and Wang, W. (2007). Vegetation history of the western Loess Plateau of China during the last $40 \mathrm{ka}$ based on pollen record (in Chinese). Acta Palaeontol. Sin. 46, 45-61. doi: 10.3969/j.issn.0001-6616.2007.01.003

Tarasov, P., Jin, G., and Wagner, M. (2006). Mid-Holocene environmental and human dynamics in northeastern China reconstructed from pollen and archaeological data. Sci. Dir. 241, 284-300. doi: 10.1016/j.palaeo.2006. 03.038

Walsh, K. (2013). The Archaeology of Mediterranean Landscapes: HumanEnvironment Interaction from the Neolithic to the Roman Period. Cambridge, CA: Cambridge University Press.

Wang, C., Lü, H., Zhang, J., Gu, Z., and He, K. (2014). Prehistoric demographic fluctuations in China inferred from radiocarbon data and their linkage with climate change over the past 50000 years. Quat. Sci. Rev. 98, 45-59. doi: 10.1016/j.quascirev.2014.05.015

Wang, G., Zhai, W., Yang, H., Wang, L., Zhong, L., Liu, Y., et al. (2016). Out of southern East Asia: the natural history of domestic dogs across the world. Cell Res. 26, 21-33. doi: 10.1038/cr.2015.147

Wang, H. (2011). Animal subsistence of the Yangshao period in the Wei River valley: a case-study from the site of Wayaogou in Shaanxi Province, China (Dissertation). University College London, London, United Kingdom.

Wang, H. (2019). The study on faunal remains from Dasikong site, Anyang, in 2016 (in Chinese) (Dissertation). Shangdong University, Ji'nan, China.

Wang, J. (2019). Research on the faunal remains of middle-late Dawenkou culture unearthed during 2017 excavation at Jiaojia site, Zhangqiu (in Chinese) (Dissertation). Shandong University, Ji'nan, China.

Wu, W., Zheng, H., Hou, M., and Ge, Q. (2018). The 5.5 cal ka BP climate event, population growth, circumscription and the emergence of the earliest complex societies in China. Sci. China Earth Sci. 61, 134-148. doi: 10.1007/s11430-017-9157-1

Xia, W., and Gao, Y. (1988). Chinese Animal Atlas-Mammals (in Chinese). Beijing: Science Press.

Xu, Q., Xiao, J., Li, Y., Tian, F., and Nakagawa, T. (2010). Pollen-based quantitative reconstruction of Holocene climate changes in the Daihai Lake Area, Inner Mongolia, China. J. Clim. 23, 2856-2868. doi: 10.1175/2009JCLI 3155.1

Xu, Q., Xiao, J., Nakamura, T., Yang, X., Zheng, Z., Liang, W., et al. (2004). Pollen evidence of vegetation and climate changes in Daihai Lake area during the Holocene (in Chinese). J. Glaciol. Geocryol. 26, 73-80. doi: 10.3969/j.issn.1000-0240.2004.01.011

Yang, C. (2006). The research of the animal remains of Xicha site in Inner Mongolia (in Chinese) (Dissertation). Jilin University, Changchun, China.

Yang, J. (2006). The zooarchaeological research of Erlitou site in Yanshi, Henan Province (in Chinese) (Dissertation). Graduate School of Chinese Academy of Social Sciences, Beijing, China.
Yang, M. (2018). The animal remains research of Shangpo site in Xiping country in Henan Province (in Chinese) (Dissertation). Henan University, Kaifeng, China.

Yang, Y., Zhang, S., Oldknow, C., Qiu, M., Chen, T., Li, H., et al. (2019). Refined chronology of prehistoric cultures and its implication for re-evaluating humanenvironment relations in the Hexi Corridor, northwest China. Sci. China Earth Sci. 62, 1578-1590. doi: 10.1007/s11430-018-9375-4

Yi, S., Saito, Y., Oshima, H., Zhou, Y., and Wei, H. (2003). Holocene environmental history inferred from pollen assemblages in the Huanghe (Yellow River) delta, China: climate change and human impact. Quat. Sci. Rev. 22, 609-628. doi: 10.1016/S0277-3791(02)00086-0

You, Y., Wang, J., Zhao, X., Ling, X., Chen, X., Ma, J., et al. (2014). A zooarchaeological research on bactrian camel bones in the Shirenzigou Site, Xinjiang. Quat. Sci. 34, 173-186. doi: 10.3969/j.issn.1001-7410.2014.21

You, Y., Yuan, G., Zhao, Y., and Jing, S. (2017). Research of faunal remains from Meishan site in Linru County, Henan Procince (in Chinese). Cult. Relics Southern China. 3, 165-176. doi: 10.3969/j.issn.1004-6275.2017.03.023

$\mathrm{Yu}, \mathrm{C}$. (2011). The identification and research of animal remains of Xishan site in Li County, Gansu Province (in Chinese). Cult. Relics Southern China 3, 73-79.

Yuan, J. (2010). Zooarchaeological study on the domestic animals in ancient China. Quat. Sci. 30, 298-306. doi: 10.3969/j.issn.1001-7410.2010.02.06

Zhao, C. (2009). A study on the faunal remains of prehistoric period in Guanzhong Region (in Chinese) (Dissertation). Jinlin University, Changchun, China.

Zhao, H., Chen, F., Li, S., Wintle, A. G., Fan, Y., and Xia, D. (2007). A record of holocene climate change in the Guanzhong basin, China, based on optical dating of a loess-palaeosol sequence. Holocene 17, 1015-1022. doi: $10.1177 / 0959683607080530$

Zhao, Y., and Yu, Z. (2012). Vegetation response to Holocene climate change in East Asian monsoon-margin region. Earth Sci. Rev. 11, 31-10. doi: 10.1016/j.earscirev.2012.03.001

Zhao, Z. (2011). New archaeobotanic data for the study of the origins of agriculture in China. Curr. Anthropol. 52, S295-S306. doi: 10.1086/659308

Zhao, Z. (2014). The process of origin of agriculture in China: archaeological evidence from flotation results (in Chinese). Quat. Sci. 34, 73-84. doi: 10.3969/j.issn.1001-7410.2014.01.10

Zhao, Z. (2017). The development of agriculture in the time of Yangshao culture and the establishment of agricultural society: an analysis on the flotation result of Yuhuazhai site (in Chinese). Jianghan Archaeol. 153, 98-108.

Zhao, Z. (2019). Introduction of the origin of agriculture in China (in Chinese). Res. Herit. Preserv. 4, 1-7. doi: 10.3969/j.issn.2096-0913.2019. 01.001

Zhou, A., Sun, H., Chen, F., Zhao, Y., An, C., Dong, G., et al. (2010). High resolution climate change in mid-late Holocene on Tianchi Lake, Liupanshan mountain in the Loess Plateau in central China and its significance. Chin. Sci. Bull. 55, 2118-2121. doi: 10.1007/s11434-010-3226-0

Zhou, B. (1994). The Indentification Report of Faunal Remains From Baijiacun Site (in Chinese), ed L. Baijiacun. Sichuan: Institute of Archaeology, Chinese Academy of Social Sciences, Bashu Books, 123-126.

Zhou, L., and Garvie-Lok, S. J. (2015). Isotopic evidence for the expansion of wheat consumption in northern China. Archaeol. Res. Asia 4, 25-35. doi: $10.1016 /$ j.ara.2015.10.001

Conflict of Interest: The authors declare that the research was conducted in the absence of any commercial or financial relationships that could be construed as a potential conflict of interest.

Copyright (c) $2020 \mathrm{Du}, \mathrm{Ma}, \mathrm{Lu}$, Dong and Dong. This is an open-access article distributed under the terms of the Creative Commons Attribution License (CC BY). The use, distribution or reproduction in other forums is permitted, provided the original author(s) and the copyright owner(s) are credited and that the original publication in this journal is cited, in accordance with accepted academic practice. No use, distribution or reproduction is permitted which does not comply with these terms. 